\title{
Performance of minimally invasive sagittal synostectomy with supine patient positioning: technical note
}

\author{
Jonathan E. Martin, MD, ${ }^{1,3}$ Thomas Manning, MD, ${ }^{2}$ Markus Bookland, MD,, 3 and \\ Charles Castiglione, $\mathrm{MD}^{3}$

\begin{abstract}
'Department of Surgery, Division of Neurosurgery; ${ }^{2}$ Department of Anesthesiology; and ${ }^{3}$ Department of Surgery, Division of Craniofacial Surgery, Connecticut Children's Medical Center, Hartford, Connecticut
\end{abstract}

\begin{abstract}
OBJECTIVE Minimally invasive (MI) synostectomy with postoperative helmet orthosis is increasingly used in the management of sagittal craniosynostosis. Although the $\mathrm{MI}$ technique reduces or eliminates the need for access to the lateral skull surface, the modified prone/sphinx position remains popular. The authors present their initial experience with supine positioning for Ml sagittal synostectomy.

METHODS The authors used supine positioning with the head turned laterally on a horseshoe head holder in 5 consecutive patients undergoing MI sagittal synostectomy.
\end{abstract}

RESULTS Resection of the sagittal suture from the anterior to posterior fontanel was accomplished in all patients. Surgical time averaged 70 minutes. No patient required transfusion. The posttreatment cephalic index averaged $83 \%$.

CONCLUSIONS Initial experience with supine positioning for MI sagittal synostectomy suggests that the technique can be used as an alternative to the modified prone position, with the potential to reduce anesthetic risk in these patients.

https://thejns.org/doi/abs/10.3171/2018.5.PEDS18200

KEYWORDS minimally invasive; craniosynostosis; positioning; craniofacial; surgical technique

$\mathrm{M}$ INIMALLY invasive (MI) synostectomy with postoperative helmet orthosis is increasingly used by neurosurgical providers in the management of sagittal craniosynostosis diagnosed in infancy. Since its introduction in the 1990s $\mathrm{s}^{1}$ the technique has evolved, with many practitioners using a limited osteotomy overlying the sagittal suture. ${ }^{9}$ Excellent cosmetic outcomes have been demonstrated with the use of a limited midline craniectomy without the use of lateral barrel-stave osteotomies. ${ }^{3,11}$ Despite this reduction in need to access the lateral skull surface, modified prone/sphinx positioning ${ }^{10}$ remains popular with many craniofacial teams performing this intervention.

Prone positioning is associated with potential risks. ${ }^{6}$ Intraoperative extubation in the modified prone position presents the potential for catastrophic anoxic injury. ${ }^{2} \mathrm{Cer}-$ vical hyperextension can result in neurological injury in the setting of congenital craniocervical spinal abnormali- ties, to include segmentation anomalies and Chiari malformation. Alternative patient positioning with comparable access to the midline may enhance patient safety in this surgical population.

\section{Methods}

\section{Patient Population}

We conducted an institutional review board-exempted retrospective review of 5 patients undergoing MI strip suturectomy performed by a single surgeon (J.E.M.) for sagittal synostosis. Preoperative and postoperative anthropometric data were extracted from optical scanning performed by the collaborating orthotist (Fig. 1). No radiographs were obtained pre- or postoperatively. Clinical data including surgery duration, need for transfusion, and length of hospitalization were collected from the electronic medical record. 


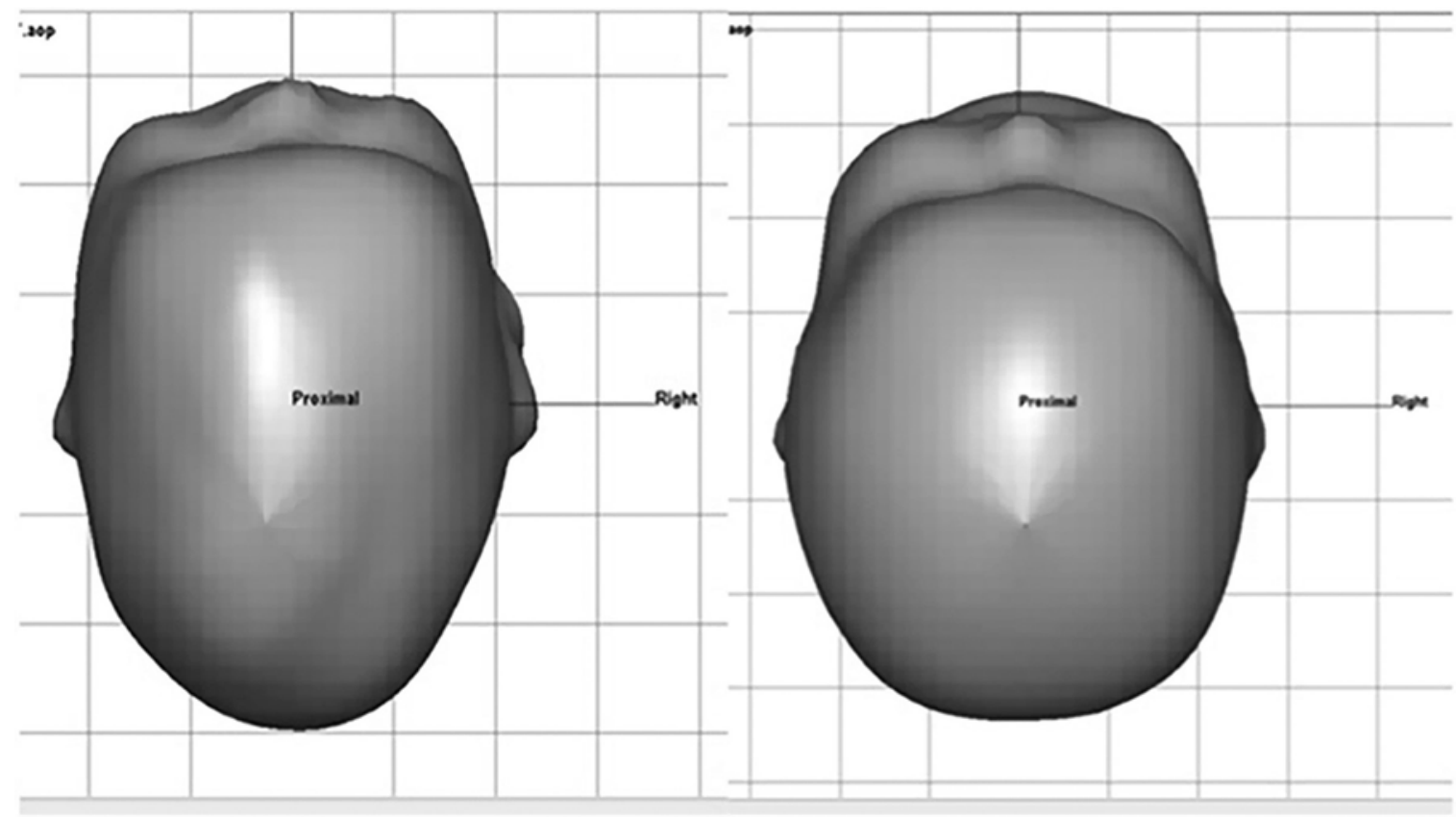

FIG. 1. Presurgical (left) and 6-month postsurgical (right) optical scans demonstrating outcome following MI synostectomy in the patient in case 1.

\section{Surgical Technique}

Anesthetic induction was performed to include endotracheal intubation and intravenous access. No arterial line was used. No precordial Doppler monitoring was performed. All patients received a preprocedure bolus of 10 $\mathrm{mg} / \mathrm{kg}$ tranexamic acid followed by an infusion of $5 \mathrm{mg} /$ $\mathrm{kg} / \mathrm{hr}$. Patients were positioned supine with lateral head rotation on a cerebellar head holder (Fig. 2). The midline vertex was maintained at the level of the heart to minimize the risk of air embolism. A narrow vertex suturectomy was then performed as described by Dlouhy et al. ${ }^{3}$ We used two transverse incisions, one just posterior to the anterior fontanel and the other anterior to the lambda. A

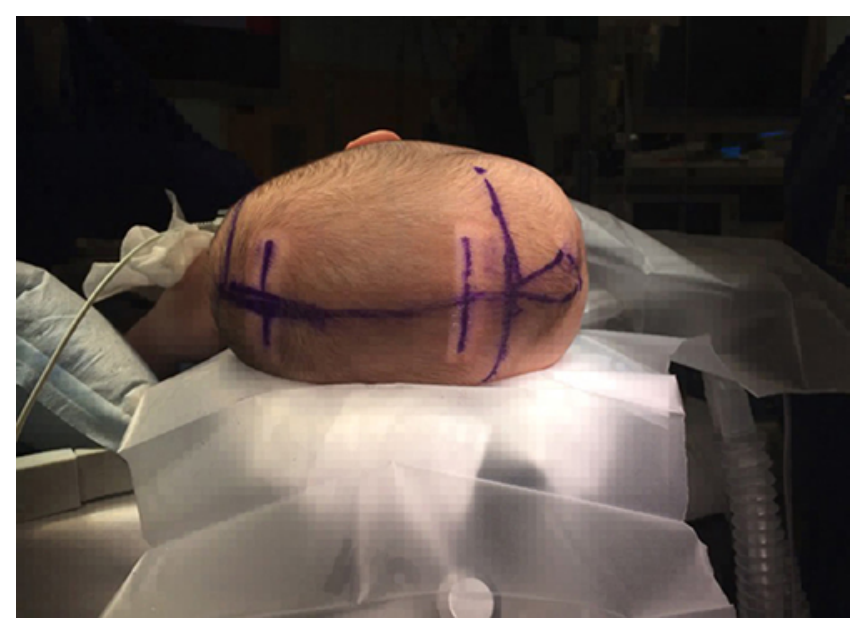

FIG. 2. Supine positioning for MI sagittal synostectomy. Figure is available in color online only. lighted handheld retractor was used to develop the subgaleal plane between the two incisions. We created 2-cm trough osteotomies with a high-speed drill across the midline. Following removal of a short segment of bone with Leksell rongeurs, the epidural plane was easily developed under direct vision, with the remaining bridge of bone removed with Mayo scissors. Hemostasis was maintained with injectable Gelfoam. Following irrigation, layered closure was performed with absorbable suture.

\section{Helmeting}

Patients were evaluated by the orthotist prior to surgery. A cranial orthosis was provided to each patient within 1 week of surgery. In partnership with the orthotics technician, patients were monitored for fit and compliance during therapy. Orthotic treatment was continued at the discretion of the parents and treating surgeon for a minimum of 6 months, with goals of 1) cephalic index $>0.8$, and/or 2) parental satisfaction with the aesthetic result.

\section{Statistical Analysis}

Descriptive statistical analysis was performed on variables including preoperative cephalic index, surgery duration, transfusion volume, length of hospitalization, and postoperative cephalic index.

\section{Results}

Data for 5 consecutive patients undergoing narrow vertex suturectomy with supine positioning were reviewed. The series included 3 boys and 2 girls. The mean age was 2.8 months (range 1.5-4.5 months). Weight at the time of surgery averaged $5.4 \mathrm{~kg}$ (range $3.8-6.1 \mathrm{~kg}$ ). The mean preoperative cephalic index was $70.4 \%$. Surgical time ranged 
TABLE 1. Demographic and operative characteristics of 5 patients undergoing MI synostectomy with supine positioning

\begin{tabular}{lccccc}
\hline & \multicolumn{5}{c}{ Case No. } \\
\cline { 2 - 6 } \multicolumn{1}{c}{ Characteristic } & 1 & 2 & 3 & 4 & 5 \\
\hline Sex & $\mathrm{M}$ & $\mathrm{F}$ & $\mathrm{F}$ & $\mathrm{M}$ & $\mathrm{M}$ \\
\hline Age (mos) & 4.5 & 2 & 2.5 & 3.5 & 1.5 \\
\hline Weight (kg) & 6 & 5 & 5.9 & 6.1 & 3.8 \\
\hline Length of stay (days) & 2 & 2 & 1 & 2 & 2 \\
\hline Surgical time (mins) & 81 & 65 & 65 & 67 & 71 \\
\hline Transfusion (ml) & 0 & 0 & 0 & 0 & 0 \\
\hline Crystalloid (ml) & 200 & 180 & 200 & 100 & 60 \\
\hline Preop Hct (\%) & 36.5 & 37.3 & 32.7 & 32.1 & 39.6 \\
\hline POD 1 Hct (\%) & 25.9 & 26.5 & 21.4 & 23.8 & 33 \\
\hline Preop Cl (\%) & 76 & 69 & 67 & 70 & 70 \\
\hline Posttreatment Cl (\%) & 84 & 87 & 82 & 80 & 82 \\
\hline Cl
\end{tabular}

$\mathrm{Cl}=$ cephalic index; $\mathrm{Hct}=$ hematocrit; $\mathrm{POD}=$ postoperative day.

from 65 to 81 minutes (mean 69.8 minutes). No intraoperative or postoperative transfusions were required. Postoperative day 1 hematocrit averaged $26.1 \%$ (range $21.4 \%$ $33 \%$ ). The mean length of stay was 1.8 days. The mean 6-month postsurgical cephalic index was 83\% (Table 1).

\section{Discussion}

Use of MI suturectomy with postoperative orthotic management has emerged as a safe and effective technique for the management of craniosynostosis in the infant. The technique has evolved over the past 15 years from a wide vertex craniectomy with lateral barrel-stave osteotomies to the more limited technique of narrow vertex suturectomy, with equivalent cosmetic outcome. ${ }^{3}$ This more limited surgical technique obviates the need for lateral calvarial access.

The modified sphinx position is commonly used for surgery in the patient with sagittal synostosis. Positioning devices have evolved from the beanbag initially described by Park et al. ${ }^{10}$ to the DORO head holder (Pro Med Instruments) used in most contemporary series. Regardless, the prone position is independently associated with increased patient risk.

Airway complications arising from prone positioning are rare but challenging intraoperative events. Although the incidence of intraoperative extubation in MI surgery for craniosynostosis is unknown, a recent review of complications during craniofacial surgery estimated inadvertent extubation occurs in more than $1 \%$ of cases..$^{12}$ Endotracheal tube displacement can occur due to gravitational effects or as a result of facial movement during dissection and/or bone removal. ${ }^{6}$ Airway management tasks that are straightforward in the supine patient become more complex in the prone position, ${ }^{4}$ with the potential for catastrophic results. Alternative patient positioning in the supine position may enhance patient safety for MI sagittal synostectomy.

Venous air embolism is a commonly reported complication of surgical procedures in patients in the prone position. A study by Faberowski et al. found the frequency of venous air embolism to be $82.6 \%$ during craniectomy for craniosynostosis repair, as detected by precordial Doppler. ${ }^{5}$ Although most venous air emboli are asymptomatic, the potential for serious consequences exists. Elevation of the head above the heart can cause a pressure gradient promoting air entrapment into open noncompressible veins and subsequent hemodynamic instability. Furthermore, in the presence of a patent foramen ovale, venous air emboli can result in neurological sequelae. ${ }^{8}$

The sphinx position also produces neck extension that poses a theoretical risk of cervical spine injury in selected patients. ${ }^{7}$ Underlying pathology such as Chiari malformation or cervical segmentation anomaly may result in narrowing of the cervical canal, placing the patient at increased risk of spinal cord injury from operative positioning. Many centers, including our own, have reduced or eliminated preoperative imaging studies from the evaluation of many patients with single-suture synostosis. Although diagnostic imaging of the patient with craniosynostosis may allow for detection of these at-risk patients, supine positioning avoids risks associated with radical neck extension during positioning.

MI resection of the sagittal suture requires access to the midline, which can easily be obtained in either the modified prone or supine position. Supine positioning requires no specialty head-holding system. It places the endotracheal tube in a nondependent position that is more accessible to the anesthesia team. Comparison of surgical times in this series to patients undergoing MI sagittal synostectomy in published series were similar, ${ }^{3,9,11}$ with no patients requiring transfusion.

\section{Conclusions}

In this series, MI synostectomy for sagittal craniosynostosis was performed with supine patient positioning without impact on operative course or patient outcome. Surgical duration was comparable to literature-based norms for performance in the prone position. No transfusions were required. Supine positioning offers potential advantages including reduced anesthetic risk in this patient population, and may be considered as an option by craniofacial surgeons performing MI synostectomy for sagittal craniosynostosis.

\section{Acknowledgments}

We thank Ms. Megan Chamis and Ms. Deanna Ourand for the outstanding orthotic support they provide to our patients.

\section{References}

1. Barone CM, Jimenez DF: Endoscopic craniectomy for early correction of craniosynostosis. Plast Reconstr Surg 104:1965-1975, 1999

2. Cook TM, MacDougall-Davis SR: Complications and failure of airway management. Br J Anaesth 109 (Suppl 1):i68-i85, 2012

3. Dlouhy BJ, Nguyen DC, Patel KB, Hoben GM, Skolnick GB, Naidoo SD, et al: Endoscope-assisted management of sagittal synostosis: wide vertex suturectomy and barrel stave osteotomies versus narrow vertex suturectomy. J Neurosurg Pediatr 25:674-678, 2016

4. Edgcombe H, Carter K, Yarrow S: Anaesthesia in the prone position. Br J Anaesth 100:165-183, 2008 
5. Faberowski LW, Black S, Mickle JP: Incidence of venous air embolism during craniectomy for craniosynostosis repair. Anesthesiology 92:20-23, 2000

6. Kwee MM, Ho YH, Rozen WM: The prone position during surgery and its complications: a systematic review and evidence-based guidelines. Int Surg 100:292-303, 2015

7. Lanier WL, Warner MA: New perioperative cervical injury: medical and legal implications for patients and anesthesia providers. Anesthesiology 114:729-731, 2011

8. Mirski MA, Lele AV, Fitzsimmons L, Toung TJ: Diagnosis and treatment of vascular air embolism. Anesthesiology 106:164-177, 2007

9. Nguyen DC, Farber SJ, Skolnick GB, Naidoo SD, Smyth MD, Kane AA, et al: One hundred consecutive endoscopic repairs of sagittal craniosynostosis: an evolution in care. J Neurosurg Pediatr 20:410-418, 2017

10. Park TS, Haworth CS, Jane JA, Bedford RB, Persing JA: Modified prone position for cranial remodeling procedures in children with craniofacial dysmorphism: a technical note. Neurosurgery 16:212-214, 1985

11. Ridgway EB, Berry-Candelario J, Grondin RT, Rogers GF, Proctor MR: The management of sagittal synostosis using endoscopic suturectomy and postoperative helmet therapy. J Neurosurg Pediatr 7:620-626, 2011

12. Stricker PA, Goobie SM, Cladis FP, Haberkern CM, Meier PM, Reddy SK, et al: Perioperative outcomes and management in pediatric complex cranial vault reconstruction: a multicenter study from the pediatric craniofacial collaborative group. Anesthesiology 126:276-287, 2017

\section{Disclosures}

The authors report no conflict of interest concerning the materials or methods used in this study or the findings specified in this paper.

\section{Author Contributions}

Conception and design: Martin. Acquisition of data: Martin, Bookland. Analysis and interpretation of data: Martin. Drafting the article: Martin, Manning. Critically revising the article: all authors. Reviewed submitted version of manuscript: all authors. Approved the final version of the manuscript on behalf of all authors: Martin.

\section{Supplemental Information \\ Previous Presentations}

Portions of this work were presented in poster form at the 2017 Congress of Neurological Surgeons Annual Meeting, Boston, MA, October 7-11, 2017.

\section{Correspondence}

Jonathan E. Martin: University of Connecticut School of Medicine, Connecticut Children's Medical Center, Hartford, CT. jmartin03@ccmckids.org. 